\title{
Association between VDR and ESR1 gene polymorphisms with bone and obesity phenotypes in Chinese male nuclear families
}

Jie-mei GU, Wen-jin XIAO, Jin-wei HE, Hao ZHANG, Wei-wei HU, Yun-qiu HU, Miao LI, Yu-juan LIU, Wen-zhen FU, Jin-bo YU, Gao GAO, Hua YUE, Yao-hua KE, Zhen-lin ZHANG*

Department of Osteoporosis, Metabolic Bone Disease and Genetics Research Unit, The Shanghai Sixth People's Hospital, Shanghai Jiaotong University, Shanghai 200233, China

\begin{abstract}
Aim: The goal of this study was to determine whether polymorphisms in the vitamin D receptor (VDR) and estrogen receptor alpha (ESR1) genes are associated with variations of peak bone mineral density (BMD) and obesity phenotypes in young Chinese men. Methods: A total of 1215 subjects from 400 Chinese nuclear families were genotyped by polymerase chain reaction-restriction fragment length polymorphism (PCR-RFLP) and allele-specific multiple PCR (ASM-PCR) analysis at the Apal, Fokl, and CDX2 sites in the VDR gene and the Pvull and Xbal sites in the ESR1 gene. BMD at the lumbar spine and hip, total fat mass, and total lean mass were measured using dual energy X-ray absorptiometry. The associations between VDR and ESR1 gene polymorphisms with peak BMD, body mass index (BMI), total fat mass, total lean mass, and percentage fat mass (PFM) were determined using quantitative transmission disequilibrium tests (QTDTs).

Results: Using QTDTs, no significant within-family associations were obtained between genotypes or haplotypes of the VDR and ESR1 genes and peak BMD. For the obesity phenotypes, the within-family associations were significant between CDX2 genotypes and BMI $(P=0.046)$, fat mass $(P=0.004)$, and PFM $(P=0.020)$. Further, $P$ vull was significantly associated with the variation of fat mass and PFM $(P=0.002$ and $P=0.039$, respectively). A subsequent 1000 permutations were in agreement with these within-family association results.

Conclusion: Our findings showed that VDR and ESR1 polymorphisms were associated with total fat mass in young Chinese men, but we failed to find a significant association between VDR and ESR1 genotypes and peak BMD. These findings suggested that the VDR and ESR1 genes are quantitative trait loci (QTL) underlying fat mass variation in young Chinese men.
\end{abstract}

Keywords: VDR; ESR1; polymorphism; bone mineral density; fat mass; lean mass; transmission disequilibrium test

Acta Pharmacologica Sinica (2009) 30: 1634-1642; doi: 10.1038/aps.2009.169

\section{Introduction}

Osteoporosis and obesity are two common complex diseases and major health problems. It is also known that obesity and osteoporosis are closely related diseases ${ }^{[1]}$. Human body composition generally changes with aging, mainly including a reduction in lean body mass, an accumulation of fat body mass, and a loss of bone mass ${ }^{[2]}$. These changes may correspondingly lead to osteoporosis and obesity. Both bone mass and obesity phenotypes are known to be under strong genetic regulation ${ }^{[3,4]}$. In the past decade, a number of candidate genes have been identified that may contribute to bone mineral density (BMD), but far less is known about genes affect-

\footnotetext{
* To whom correspondence should be addressed.

E-mail ZZL2002@medmail.com.cn

Received 2009-09-24 Accepted 2009-10-22
}

ing obesity phenotypes such as lean mass and fat mass ${ }^{[5,6]}$. Recently, Tang et al ${ }^{[7]}$ conducted a bivariate whole-genome linkage scan and identified several genomic regions shared by obesity and osteoporosis.

The vitamin $\mathrm{D}$ receptor $(V D R)$ is one of the most extensively studied genes in relation to BMD, due to the important role of vitamin $\mathrm{D}$ in bone metabolism ${ }^{[8]}$. A functional genetic polymorphism in $V D R$ could be involved in other tissues that respond to vitamin $\mathrm{D}$, such as muscle cells and adipocytes. Indeed, it has been demonstrated that vitamin D stimulates the differentiation of preadipocytes to adipocytes in the OB 17 cell line $\mathrm{e}^{[9]}$. Some studies have also suggested that VDR genotype may function as a determinant of body composition ${ }^{[3]}$.

Estrogen receptor alpha (ESR1) is also an important potential candidate gene for osteoporosis, and extensive studies have been performed on the relationship between polymorphisms 
of this gene and BMD variation. The ESR1 gene is known to be involved in metabolic pathways influencing body growth, which may correlate with body mass index $(\mathrm{BMI})^{[10,11]}$. One study demonstrated the association of ESR1 polymorphisms with body fat distribution in Japanese women ${ }^{[12]}$. Another study in Caucasians found PvuII polymorphisms within the ESR1 gene to be associated with BMI, with the PvuII genotype giving rise to the highest BMI values in postmenopausal women $^{[13]}$.

All of the above data indicate that the VDR and ESR1 genes could be pleiotropic genetic factors influencing both osteoporosis and obesity phenotypes. However, until now, the clear relationship between polymorphisms in the VDR and ESR1 genes with peak BMD and obesity phenotypes have not been elucidated. In this study, we investigated three $V D R$ loci and two ESR1 loci with peak BMD, BMI, total fat mass and total lean mass in Chinese male nuclear families. Dual-energy $\mathrm{X}$-ray absorptiometry (DXA) is a precise, accurate, non-invasive, safe, and convenient technique, found on a three compartment model separating the body into total body mineral mass, fat mass, and lean mass ${ }^{[14,15]}$. Most association studies use traditional association approaches in random population, and such study designs are prone to population stratification/ admixture, which produces false positive/negative results. In addition, the linkage approach often lacks statistical power with the currently used sample. However, the transmission disequilibrium test (TDT), a family-based association approach, is immune to population stratification, much more powerful compared with the traditional linkage approach, and can be used in nuclear families with or without parental phenotypes. Thus, in this study, we used quantitative transmission disequilibrium tests (QTDTs) to determine whether VDR and ESR1 polymorphisms were associated with peak BMD and obesity phenotypes in a relatively large sample of Chinese male nuclear families.

\section{Materials and methods Subjects}

All subjects involved in the study were collected by the Department of Osteoporosis of Shanghai Jiao Tong University Affiliated Sixth People's Hospital from the local population of Shanghai City (located on the mid-east coast of China) and signed informed consent documents before entering the project. Between 2004 and 2007, we recruited 1296 individuals from 427 male nuclear families whose offspring were sons. Of these, samples from 15 individuals could not be amplified and discriminated genotypes due to the poor quality of the DNA, and 12 sons deviated from Mendelian inheritance. Thus, there were a total of 400 male nuclear families composed of both parents and at least one healthy male child (1215 individuals) whose ages were largely between 20 to 40 years old. The average family size was 3.03; 385 families had one child and 15 families had 2. For each study subject, we also collected information on age, sex, medical history, family history, marital status, physical activity, alcohol use, diet habits and smoking history. The recruited sons were healthy. The exclusion crite- ria for the study subjects were a history of: (1) serious residual effects of cerebral vascular disease; (2) diabetes mellitus, except for easily controlled, non-insulin-dependent diabetes mellitus (defined as adult asymptomatic hyperglycemia controlled by diet or oral agents); (3) chronic renal disease manifested by a serum creatinine level of $11.9 \mathrm{mg} / \mathrm{dl}$; (4) chronic liver disease or alcoholism; (5) chronic lung disease; (6) 12 weeks of corticosteroid therapy at pharmacologic levels; (7) 16 months of treatment with anticonvulsant therapy; (8) evidence of other metabolic or inherited bone diseases (eg, hyper- or hypoparathyroidism, Paget's disease of bone, osteomalacia, or osteogenesis imperfecta); (9) rheumatoid arthritis or collagen disease; (10) major gastrointestinal disease (eg, peptic ulcer, malabsorption, chronic ulcerative colitis, regional enteritis, or any significant chronic diarrhea state); (11) significant disease of any endocrine organ that would affect bone mass (eg, diabetes, hyperthyroidism, etc); (12) any neurologic or musculoskeletal condition that would be a nongenetic cause of low bone mass; and (13) any disease, treatment, or condition that would be a nongenetic cause of low bone mass ${ }^{[16]}$.

\section{Phenotype measurements}

The BMD $\left(\mathrm{g} / \mathrm{cm}^{2}\right)$ of the lumbar spine and left proximal femur including lumber spine 1-4 (L1-4), femoral neck, total hip, total fat mass $(\mathrm{kg})$, and total lean mass $(\mathrm{kg})$ were measured by a Lunar Prodigy DXA densitometer (Lunar Corp, Madison, WI), and data were analyzed by Prodigy encore software (ver.6.70, standard-array, mode). The percentage of fat mass (PFM) was calculated as the ratio of fat mass to body weight ${ }^{[17]}$. The DXA scanner was on fan-beam mode. The machine was calibrated daily, and the coefficient of variability $(\mathrm{CV})$ values of the DXA measurements (which were obtained from 15 individuals repeatedly measured three times) were: for lumbar spine, $1.39 \%$; for femoral neck, $2.22 \%$; for total hip, $0.70 \%$; and for trochanter, $1.41 \%{ }^{[18]}$. For body composition, the $C V$ s were $1.18 \%$ and $3.72 \%$ for total lean mass and fat mass, respectively. The long-term reproducibility of our DXA data during the trial, based on weekly repeated phantom measurements, was $0.45 \%{ }^{[4]}$. Body mass index (BMI) was defined as the weight/ height ${ }^{2}$ in units of $\mathrm{kg} / \mathrm{m}^{2}$.

\section{Genotyping}

Genomic DNA was isolated using the phenol-chloroform extraction method. Genotypes were detected using polymerase chain reaction-restriction fragment length polymorphism (PCR-RFLP) and allele-specific multiple PCR (ASMPCR). The primers are shown in Table 1. A $265 \mathrm{bp}$ fragment containing the FokI (rs10735810) polymorphism in the start codon of the VDR gene was amplified by $\mathrm{PCR}^{[19]}$. The FokI genotypes were identified by electrophoresis of the DNA samples in $1.5 \%$ agarose gels. The FokI genotypes were named as follows: FF (absence of the restriction site); ff (presence of the restriction site); Ff (heterozygous for the restriction site). A 740 bp fragment containing the ApaI (rs7975232) polymorphism near the $3^{\prime}$-end of the VDR gene was amplified by $\mathrm{PCR}^{[20]}$. The ApaI genotypes were named as follows: AA (absence of 
Table 1. Information of the analyzed SNPs in this study.

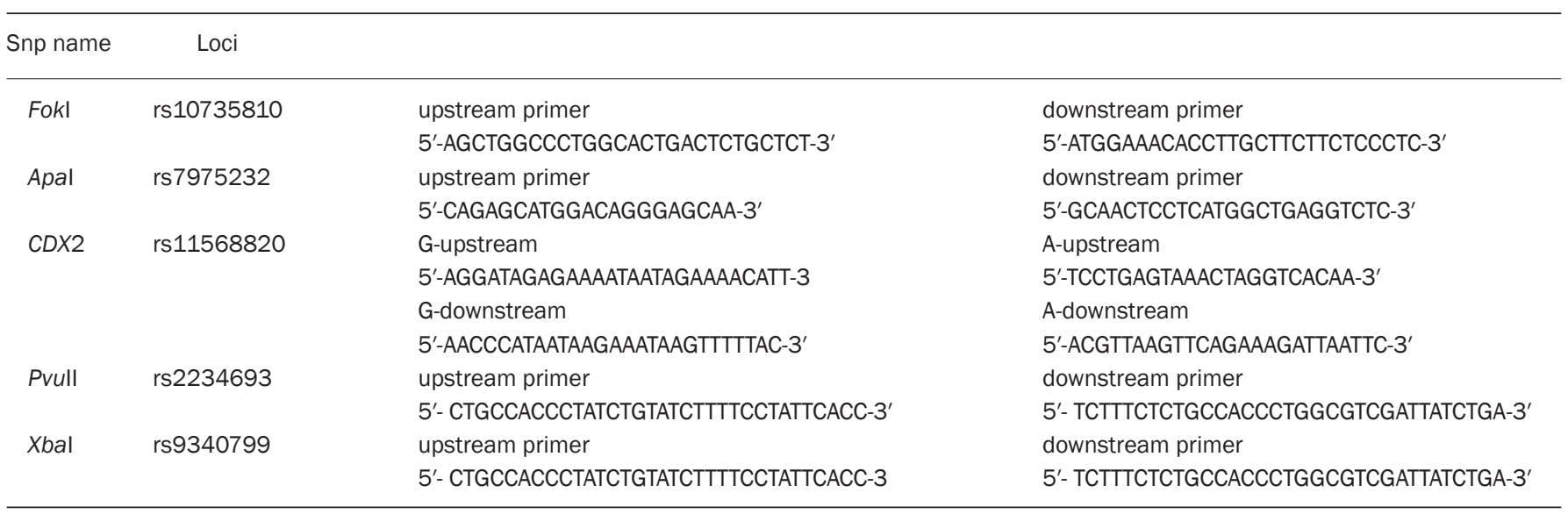

the restriction site); aa (presence of the restriction site); Aa (heterozygous for the restriction site). The CDX2 (rs11568820) polymorphism was determined using allele-specific multiple PCR (ASM-PCR) according to the method established by Fang et $a l^{[21]}$. The position of the CDX2 polymorphism is located in the promoter region of the VDR gene. Two sets of primers were designed for the ASM-PCR tests: These four primers generate three PCR fragments: primer set G-upstream and G-downstream specifically amplifies the $G$ allele with a size of $110 \mathrm{bp}$; A-upstream and A-downstream specifically amplify the A-allele with a size of $235 \mathrm{bp}$; and the out-primer pair (G-upstream and A-downstream) amplifies the internal control PCR fragment with a size of $297 \mathrm{bp}$. Therefore, the GG genotype produced $297 \mathrm{bp}$ and $110 \mathrm{bp}$ fragments, the AA genotype produced $297 \mathrm{bp}$ and $235 \mathrm{bp}$ fragments, and the AG genotype produced $297 \mathrm{bp}, 235 \mathrm{bp}$ and $110 \mathrm{bp}$ fragments ${ }^{[22]}$. PCR products were size-separated on a $2.5 \%$ agarose gel. A $1.3 \mathrm{~kb}$ fragment containing the PvuII (rs2234693) and XbaI (rs9340799) polymorphisms in intron 1 of the ESR1 gene was amplified by PCR ${ }^{[23]}$. The PCR products were digested with PvuII and XbaI, respectively, and separated by $2 \%$ agarose gel electrophoresis with ethidium bromide staining. The genotypes are represented as $\mathrm{PP}, \mathrm{Pp}$, and pp for PvuII and XX, Xx,

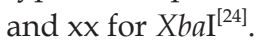

\section{Statistical analyses}

To test the population homogeneity of the study subjects, the genotype frequencies for each of the five polymorphic sites were tested against the Hardy-Weinberg equilibrium by the $\chi^{2}$ test. To ensure unrelated individual samples, only genotype data from parents of each nuclear family were used in the statistical analysis ${ }^{[25]}$. The heritability estimates were done using the linear regression of parents' mean value and offspring's value for every phenotype (described at www. heritability.com). Statistical power was estimated using Piface Software (version 1.65) (http://www.math.uiowa. edu/ rlenth/Power/) in our current sample size, according to the $\mathrm{MAF}$ (minor allele frequency) of every genotype and the variation of BMD and obesity genotypes. The QTDT program, using the orthogonal model, was used to test for population stratification, total association, linkage and withinfamily association between SNPs and haplotypes and BMD phenotypes, BMI, fat mass and lean mass. The QTDT software package is available at: http://www.sph.umich.edu/csg/ abecasis/QTDT/. This method, as implemented in the QTDT software $^{[4,26,27]}$, extends the trio-based TDT to quantitative trait data and uses genotypes data from available sibling and parents. Because in our nuclear families, all of the children were sons and the effects of parents' phenotypes were excluded in the QTDTs, sex was not used as a covariate to adjust the sons' bone phenotype variation ${ }^{[4,25]}$. Of course, raw BMD values were adjusted by age, height and weight as covariates. The BMI, fat mass and lean mass were adjusted by age as a covariate. Because false-positive results can be generated in multiple tests (as in the present study) permutations (1000 simulations) were performed to generate the empirical $p$ values to assess the reliability of the results ${ }^{[28-31]}$. The QTDT program generates $P$ values for various tests via asymptotic $\chi^{2}$ distribution. $P<0.05$ was considered significant for all analyses.

In unrelated sons, differences in BMD among the genotype and haplotype groups were tested using one-way ANOVA and general linear model-ANOVA (GLM-ANOVA), adjusting for confounding variables such as age, height and weight. Differences in BMI, fat mass, lean mass and PFM among the genotypes and haplotypes groups were determined using GLM-ANOVA, adjusting for age. Statistical analyses were performed using the SPSS package, version 11.5 (SPSS, Chicago, IL, USA).

\section{Results}

There were 400 nuclear families with 1215 individuals in this study, including 800 parents and 415 sons. The general characteristics of male nuclear families are shown in Table 2, and the basic characteristics of the sons are shown in Table 3. All of the subjects were genotyped at the ApaI, FokI, CDX2, PvuII, and $\mathrm{XbaI}$ polymorphic sites. Pearson correlation analysis 
Table 2. Basic characteristics of the subjects (mean $\pm S D$ ).

\begin{tabular}{lccc}
\hline Variables & $\begin{array}{c}\text { Father } \\
(n=400)\end{array}$ & $\begin{array}{c}\text { Mother } \\
(n=400)\end{array}$ & $\begin{array}{c}\text { Son } \\
(n=415)\end{array}$ \\
\hline Age (years) & $61.1 \pm 7.1$ & $58.4 \pm 6.3$ & $30.4 \pm 6.1$ \\
Height $(\mathrm{cm})$ & $167.8 \pm 6.0$ & $155.7 \pm 5.5$ & $172.9 \pm 5.9$ \\
Weight $(\mathrm{kg})$ & $69.7 \pm 9.5$ & $58.2 \pm 8.2$ & $70.7 \pm 10.8$ \\
BMl $\left(\mathrm{kg} / \mathrm{m}^{2}\right)$ & $25.2 \pm 2.7$ & $24.0 \pm 3.1$ & $24.2 \pm 3.2$ \\
Spine BMD $\left(\mathrm{g} / \mathrm{cm}^{2}\right)$ & $1.139 \pm 0.171$ & $0.992 \pm 0.168$ & $1.138 \pm 0.137$ \\
Femoral neck BMD $\left(\mathrm{g} / \mathrm{cm}^{2}\right)$ & $0.892 \pm 0.132$ & $0.796 \pm 0.144$ & $0.995 \pm 0.141$ \\
Total hip BMD $\left(\mathrm{g} / \mathrm{cm}^{2}\right)$ & $0.958 \pm 0.138$ & $0.852 \pm 0.162$ & $1.008 \pm 0.142$ \\
FM $(\mathrm{kg})$ & - & - & $16.31 \pm 7.56$ \\
LM $(\mathrm{kg})$ & - & - & $51.43 \pm 5.76$ \\
PFM $(\%)$ & - & - & $21.9 \pm 7.3$ \\
\hline
\end{tabular}

confirmed that both fat mass and lean mass were positively correlated with BMD. According to the Pearson's coefficient $(r)$, lean mass was more strongly related to BMD (with correlations range from 0.389 to 0.508 ), and fat mass was related to BMD (with correlations range from 0.198 to 0.243 ). To determine the relative contributions of lean mass and fat mass to BMD at various sites, we performed logistic regression analysis. In agreement with the Pearson analysis, both lean mass and fat mass showed positive regression coefficients, but lean mass had a significantly greater effect on BMD than fat mass. The $r^{2}$ between lean mass and BMD ranged from 0.149 to 0.249 and was from 0.056 to 0.068 between fat mass and BMD. The distribution of all of the genotypes was in Hardy-Weinberg equilibrium. The linkage disequilibrium (LD) between PvuII and $\mathrm{XbaI}$ was not very strong $\left(\mathrm{D}^{\prime}=0.684, r^{2}=0.256\right)$. For the $V D R$ gene, the LDs between ApaI, FokI, CDX2 were all weak $\left(\mathrm{D}^{\prime}<0.1, r^{2}<0.01\right)$. Peak BMD is thought to be under strong genetic control. In our sample, the heritability estimates for peak BMD in the spine, femoral neck, and total hip were 0.565, 0.702 , and 0.693 , respectively.

We investigated the association between every genotype and BMD, BMI, fat mass and lean mass in 400 unrelated sons (randomly selected from 415 sons) using ANOVA. There was a significant association between $C D X 2$ genotypes and BMI $(P=0.006)$, and adjusted BMI values were $5.4 \%$ higher in the AA genotype compared to the AG genotype $(P=0.002)$. A significant association between $C D X 2$ genotypes and fat mass $(P=0.004)$ was found, and adjusted fat mass values were $18.8 \%$ higher in the AA genotype compared to the AG genotype $(P=0.002)$. There was a significant association between $C D X 2$ genotypes and FPM $(P=0.002)$, and adjusted PFM values were $14.8 \%$ higher in the AA genotype compared to the AG genotype $(P=0.001)$. However, no significant association was found between CDX2 genotypes and peak BMD. In addition, marginally significant association was found between the PvuII genotypes and BMD at the total hip $(P=0.049)$. Moreover, a significant association between PvuII genotypes and fat mass was observed $(P=0.022)$; adjusted fat mass values were $14.3 \%$ higher in the pp genotype compared to the Pp genotype $(P=0.006)$. A significant association between the PvuII genotypes and PFM was also observed $(P=0.020)$, and adjusted PFM values were $10.0 \%$ higher in the pp genotype compared to the Pp genotype $(P=0.006)$. (Tables 4 and 5) Analysis of these SNPs showed that genetic variations in CDX2 explained $2.40 \%, 3.08 \%$, and $3.40 \%$ of the variation in BMI, fat mass, and PFM, respectively; while PvuII explained 1.86\%, 2.18\%, and $2.12 \%$ of population variance in BMI, fat mass, and PFM, respectively.

Association between VDR and ESR1 genotypes and peak BMD were performed using the QTDT program for nuclear families. The MAF of five SNPs was $>30 \%$, and they had high

Table 3. The bacic characteristics of the sons $(n=415)$.

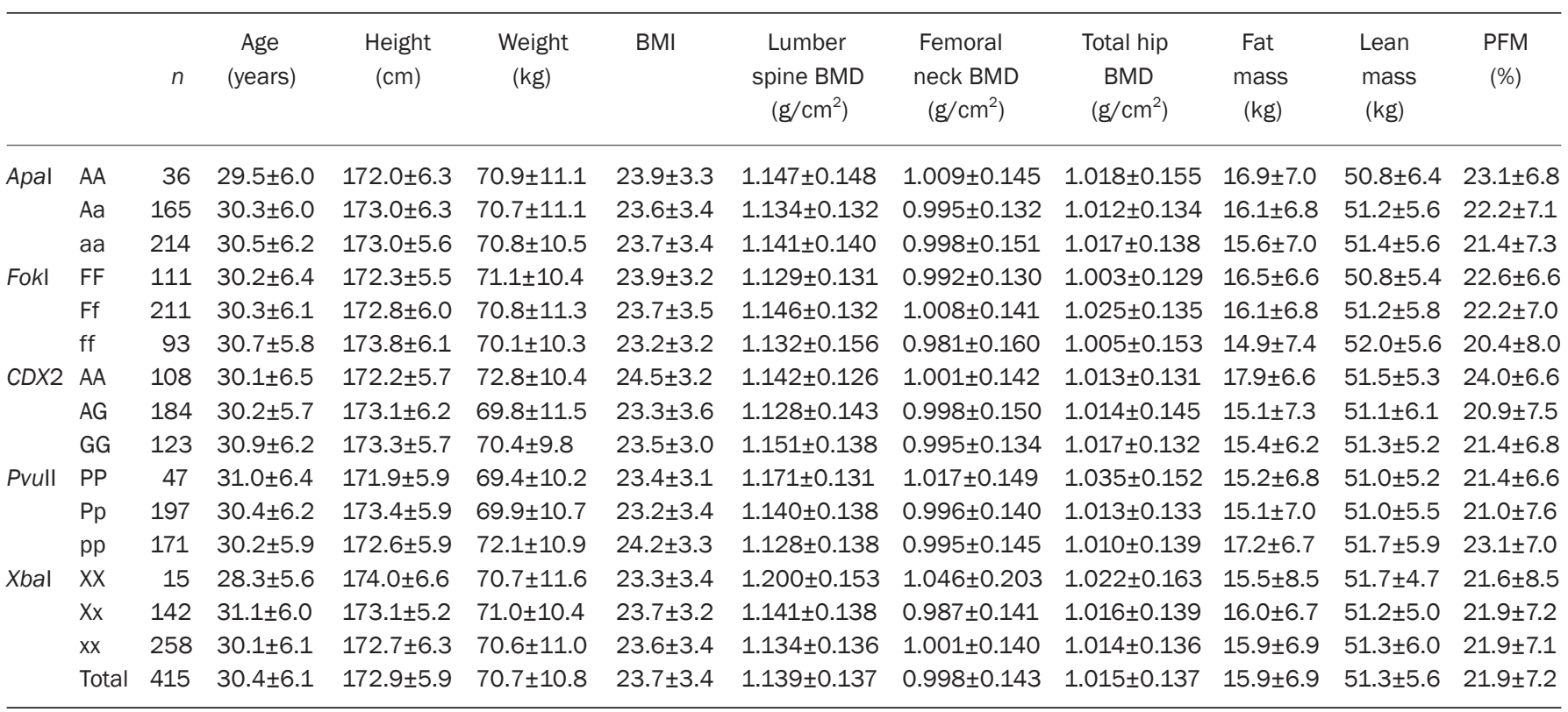


Table 4. Association of the three SNPs of VDR gene with phenotypic values in sons from one offsping (mean $\pm S D, n=400$ ). Values for BMD are raw values (means \pm SD); $P$ values are results of analysis of variance (ANOVA) test for the least square mean of BMD among various genotypes after adjusting for significant covariates of age, weight, and height. $P$ values are results of ANOVA test for the lease square mean of BMI, fat mass, lean mass among various genotypes after adjusting for significant covariates of age. Bold indicates significant $P$ values $(P<0.05)$. ${ }^{c} P<0.01$ vs $A G$ genotype. ${ }^{\mathrm{f}} P<0.01$ vs GG genotype..

\begin{tabular}{|c|c|c|c|c|c|c|c|c|c|c|c|}
\hline $\begin{array}{l}\text { Genc } \\
\text { type }\end{array}$ & o- $n$ & $\begin{array}{l}\text { Age } \\
\text { (years) }\end{array}$ & $\begin{array}{l}\text { Height } \\
(\mathrm{cm})\end{array}$ & $\begin{array}{l}\text { Weight } \\
\text { (kg) }\end{array}$ & BMI & $\begin{array}{l}\text { Lumber spine } \\
\mathrm{BMD}\left(\mathrm{g} / \mathrm{cm}^{2}\right)\end{array}$ & $\begin{array}{l}\text { Femoral neck } \\
\text { BMD }\left(\mathrm{g} / \mathrm{cm}^{2}\right)\end{array}$ & $\begin{array}{c}\text { Total hip } \\
\text { BMD }\left(\mathrm{g} / \mathrm{cm}^{2}\right)\end{array}$ & $\begin{array}{l}\text { Fat mass } \\
(\mathrm{kg})\end{array}$ & $\begin{array}{l}\text { Lean mass } \\
(\mathrm{kg})\end{array}$ & $\begin{array}{l}\text { PFM } \\
\text { (\%) }\end{array}$ \\
\hline \multicolumn{12}{|c|}{ Apal } \\
\hline AA & 36 & $29.5 \pm 6.0$ & $172.0 \pm 6.3$ & $70.9 \pm 11.1$ & $23.9 \pm 3.3$ & $1.147 \pm 0.148$ & $1.009 \pm 0.145$ & $1.018 \pm 0.155$ & $16.9 \pm 7.0$ & $50.8 \pm 6.4$ & $23.1 \pm 1.3$ \\
\hline $\mathrm{Aa}$ & 155 & $30.1 \pm 6.0$ & $173.0 \pm 6.4$ & $70.8 \pm 11.1$ & $23.6 \pm 3.4$ & $1.137 \pm 0.131$ & $0.997 \pm 0.127$ & $1.017 \pm 0.132$ & $16.1 \pm 6.8$ & $51.2 \pm 5.4$ & $22.1 \pm 0.6$ \\
\hline aа & 209 & $30.5 \pm 6.2$ & $173.1 \pm 5.6$ & $70.7 \pm 10.6$ & $23.6 \pm 3.4$ & $1.141 \pm 0.141$ & $0.995 \pm 0.152$ & $1.015 \pm 0.140$ & $15.6 \pm 7.1$ & $51.4 \pm 5.6$ & $21.4 \pm 0.5$ \\
\hline$P$ & & 0.678 & 0.64 & 0.992 & 0.83 & 0.893 & 0.938 & 0.964 & 0.574 & 0.823 & 0.383 \\
\hline \multicolumn{12}{|l|}{ Fokl } \\
\hline $\mathrm{FF}$ & 107 & $30.2 \pm 6.4$ & $172.4 \pm 5.5$ & $71.0 \pm 10.5$ & $23.9 \pm 3.2$ & $1.127 \pm 0.132$ & $0.989 \pm 0.131$ & $1.002 \pm 0.129$ & $16.4 \pm 6.6$ & $50.7 \pm 5.4$ & $22.5 \pm 6.6$ \\
\hline $\mathrm{Ff}$ & 204 & $30.1 \pm 6.1$ & $172.9 \pm 6.0$ & $70.8 \pm 11.2$ & $23.7 \pm 3.4$ & $1.148 \pm 0.132$ & $1.006 \pm 0.140$ & $1.025 \pm 0.135$ & $16.2 \pm 6.8$ & $51.2 \pm 5.7$ & $22.2 \pm 7.0$ \\
\hline $\mathrm{ff}$ & 89 & $30.6 \pm 5.8$ & $173.7 \pm 6.3$ & $70.2 \pm 10.5$ & $23.3 \pm 3.3$ & $1.137 \pm 0.156$ & $0.986 \pm 0.160$ & $1.013 \pm 0.153$ & $14.8 \pm 7.5$ & $52.1 \pm 5.6$ & $20.1 \pm 8.2$ \\
\hline$P$ & & 0.855 & 0.311 & 0.855 & 0.419 & 0.425 & 0.415 & 0.174 & 0.243 & 0.224 & 0.054 \\
\hline \multicolumn{12}{|c|}{$C D \times 2$} \\
\hline AA & 103 & $29.8 \pm 6.5$ & $172.4 \pm 5.7$ & $72.9 \pm 10.4$ & $24.5 \pm 3.2^{c}$ & $1.143 \pm 0.125$ & $1.004 \pm 0.143$ & $1.017 \pm 0.130$ & $18.0 \pm 6.6^{\text {cf }}$ & $51.7 \pm 5.2$ & $24.0 \pm 6.6^{\text {cf }}$ \\
\hline$A G$ & 180 & $30.2 \pm 5.8$ & $173.1 \pm 6.2$ & $69.7 \pm 11.7$ & $23.3 \pm 3.6$ & $1.129 \pm 0.144$ & $0.995 \pm 0.147$ & $1.014 \pm 0.144$ & $15.1 \pm 7.4$ & $51.1 \pm 6.1$ & $20.9 \pm 7.6$ \\
\hline GG & 117 & $30.8 \pm 6.2$ & $173.2 \pm 5.7$ & $70.3 \pm 9.6$ & $23.4 \pm 3.0$ & $1.154 \pm 0.137$ & $0.994 \pm 0.134$ & $1.019 \pm 0.135$ & $15.4 \pm 6.1$ & $51.2 \pm 5.1$ & $21.3 \pm 6.8$ \\
\hline$P$ & & 0.496 & 0.579 & 0.053 & 0.006 & 0.287 & 0.879 & 0.445 & 0.004 & 0.712 & 0.002 \\
\hline
\end{tabular}

Table 5. Association of the two SNPs of ESR1 gene with phenotypic values in sons from one offsping (mean $\pm S D, n=400$ ). Values for BMD are raw values (means \pm SD); $P$ values are results of analysis of variance (ANOVA) test for the least square mean of BMD among various genotypes after adjusting for significant covariates of age, weight, and height. $P$ values are results of ANOVA test for the lease square mean of BMI, fat mass, lean mass among various genotypes after adjusting for significant covariates of age. Bold indicates significant $P$ values $(P<0.05)$. ${ }^{b} P<0.05$ vs pp genotype, ${ }^{\mathrm{c}} P<0.01$ vs pp genotype. ${ }^{\mathrm{e}} P<0.05,{ }^{\mathrm{f}} P<0.01$ vs 2 .

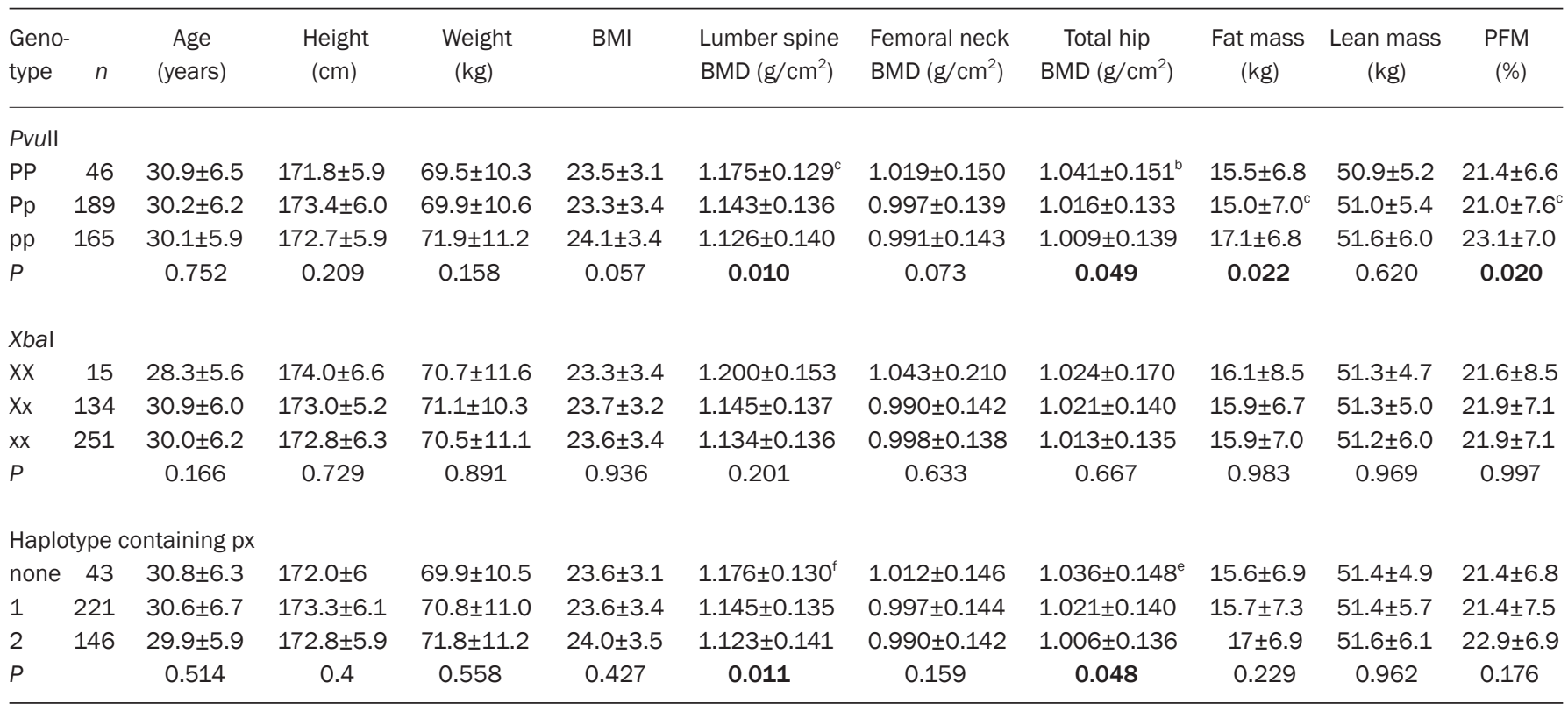

heterozygosis in our population, so we obtained 290, 309, 296, 283, and 246 informative nuclear families for the QTDT analysis for the ApaI, FokI, CDX2, PvuII, and XbaI genotypes, respec- tively. In this study, using 400 nuclear families has more than $80 \%$ of the power to test a candidate gene as a QTL, which can explain about $10 \%$ of the BMD or obesity phenotypes' varia- 
tion. The results of the QTDT analysis are presented in Table 6. There was no population stratification for the genotypes at any sites of BMD. For the total association, PvuII was associated with the variation of the lumbar spine, femoral neck and total hip $\operatorname{BMD}(P=0.008, P=0.006$, and $P=0.016$, respectively). $\mathrm{XbaI}$ genotypes were associated with the variation of the lumbar spine BMD $(P=0.040)$. For the within-family association, we did not obtain significant association evidence at any bone sites between $V D R$ or ESR1 genotypes and peak BMD at any site.

Table 6. $P$ value of tests for population stratification and within-family association between VDR, ESR1 genotypes and peak BMD. BMD values were adjusted by significant covariate effects of age, height and weight. Bold indicates significant $P$ values $(P<0.05)$.

\begin{tabular}{|c|c|c|c|c|c|}
\hline & Apal & Fokl & CDX2 & Pvull & Xbal \\
\hline \multicolumn{6}{|c|}{ Tests of population stratification } \\
\hline Lumber spine BMD & 0.478 & 0.728 & 0.725 & 0.873 & 0.450 \\
\hline Femoral neck BMD & 0.935 & 0.504 & 0.187 & 0.177 & 0.621 \\
\hline Total hip BMD & 0.554 & 0.428 & 0.288 & 0.457 & 1.000 \\
\hline \multicolumn{6}{|c|}{ Test of total association } \\
\hline Lumber spine BMD & 0.175 & 0.973 & 0.241 & 0.008 & 0.040 \\
\hline Femoral neck BMD & 0.932 & 0.279 & 0.497 & 0.006 & 0.105 \\
\hline Total hip BMD & 0.544 & 0.937 & 0.634 & 0.016 & 0.107 \\
\hline \multicolumn{6}{|c|}{ Test of within-family association } \\
\hline Lumber spine BMD & 0.969 & 0.776 & 0.817 & 0.255 & 0.098 \\
\hline Femoral neck BMD & 0.911 & 0.947 & 0.381 & 0.919 & 0.752 \\
\hline Total hip BMD & 0.822 & 0.517 & 0.472 & 0.608 & 0.446 \\
\hline \multicolumn{6}{|c|}{ P 1000 permutation of within-family association } \\
\hline Lumber spine BMD & 0.964 & 0.774 & 0.766 & 0.195 & 0.079 \\
\hline Femoral neck BMD & 0.902 & 0.943 & 0.354 & 0.907 & 0.782 \\
\hline Total hip BMD & 0.801 & 0.531 & 0.469 & 0.634 & 0.485 \\
\hline
\end{tabular}

The results of the associations between the five genotypes and obesity phenotypes in the QTDT analyses are presented in Table 7. There was population stratification between $\mathrm{XbaI}$ and fat mass $(P=0.008)$. For the total associations, $C D X 2$ and PvuII were associated with fat mass $(P=0.001$ and $P=0.009$, respectively) and PFM ( $P=0.003$ and $P=0.047$, respectively). For the within-family associations, $C D X 2$ genotypes were associated with BMI $(P=0.046)$, fat mass $(P=0.004)$, and PFM $(P=0.020)$, and $P v u I I$ genotypes were associated with the variations of fat mass and PFM ( $P=0.002$ and $P=0.039$, respectively). Considering multiple parameters were tested, 1000 permutation tests were performed, and subsequent permutations were in agreement with these significant within-family association results.

There were eight different haplotypes of the $V D R$ gene and four haplotypes of the ESR1 gene. The frequencies of the haplotypes for all parents are shown in Table 8 . We further observed the associations between VDR and ESR1 haplotypes and peak BMD using QTDTs. There was no significant
Table 7. $P$ value of tests for population stratification and within-family association between VDR, ESR1 genotypes and obesity phenotypes; BMI, total fat mass, total lean mass and PFM values were adjusted by age. Bold indicates significant $P$ values $(P<0.05)$.

\begin{tabular}{lccccc}
\hline \multicolumn{7}{c}{ Apal } & Fokl & CDX2 & Pvull & Xbal \\
\hline \multicolumn{4}{l}{ Tests of population stratification } \\
BMI & 0.442 & 0.761 & 0.114 & 0.435 & 0.634 \\
Fat mass & 0.195 & 0.919 & 0.329 & 0.080 & 0.008 \\
Lean mass & 0.960 & 0.375 & 0.379 & 0.397 & 0.456 \\
PFM & 0.306 & 0.903 & 0.595 & 0.346 & 0.099
\end{tabular}

Test of total association

$\begin{array}{llllll}\text { BMI } & 0.851 & 0.900 & 0.194 & 0.079 & 0.544 \\ \text { Fat mass } & 0.165 & 0.069 & 0.001 & 0.009 & 0.900 \\ \text { Lean mass } & 0.566 & 0.120 & 0.700 & 0.144 & 0.541 \\ \text { PFM } & 0.082 & \mathbf{0 . 0 3 0} & \mathbf{0 . 0 0 3} & \mathbf{0 . 0 4 7} & 0.807\end{array}$

Test of within-family association

$\begin{array}{llllll}\text { BMI } & 0.553 & 0.742 & 0.046 & 0.129 & 0.889\end{array}$

$\begin{array}{llllll}\text { Fat mass } & 0.059 & 0.193 & 0.004 & 0.002 & 0.049\end{array}$

$\begin{array}{llllll}\text { Lean mass } & 0.738 & 0.089 & 0.668 & 0.104 & 0.335\end{array}$

$\begin{array}{llllll}\text { PFM } & 0.067 & 0.120 & 0.020 & 0.039 & 0.158\end{array}$

$P 1000$ permutation of within-family association

\begin{tabular}{llllll} 
BMI & 0.536 & 0.741 & 0.038 & 0.129 & 0.888 \\
Fat mass & 0.110 & 0.290 & $\mathbf{0 . 0 1 2}$ & $\mathbf{0 . 0 1 3}$ & 0.127 \\
Lean mass & 0.748 & 0.063 & 0.626 & 0.108 & 0.354 \\
PFM & $\mathbf{0 . 0 4 9}$ & 0.087 & $\mathbf{0 . 0 0 9}$ & $\mathbf{0 . 0 2 3}$ & 0.153 \\
\hline
\end{tabular}

population stratification, total association, or within-family association between the VDR or ESR1 haplotypes and BMD. We also observed associations between $V D R$ haplotypes and BMI, fat mass, lean mass, and PFM using QTDTs. For haplotype 1 (aFG) and fat mass, there was population stratification $(P=0.008)$, significant total association $(P=0.022)$, and withinfamily association $(P=0.001$ and $P=0.010$ of 1000 permutation tests). For haplotype 1 (aFG) and PFM, there was significant total association $(P=0.012)$ and within-family association ( $P=0.010$ and $P=0.008$ of 1000 permutation tests). For haplotype 6 (AFA) and fat mass, there was significant total association $(P=0.018)$ and within-family association $(P=0.012$ and $P=0.041$ of 1000 permutation tests). Also, there was significant total association $(P=0.017)$ and within-family association ( $P=0.040$ and $P=0.041$ of 1000 permutation tests) for haplotype 6 (AFA) and PFM. Moreover, we investigated the association between ESR1 haplotypes and BMI, fat mass, lean mass, and PFM using QTDTs. For haplotype 1 (px) and fat mass, there was population association $(P=0.011)$ and significant withinfamily association $(P=0.002$ and $P=0.009$ of 1000 permutation tests) (data not shown).

In addition, we also investigated associations between the most common haplotypes of the two genes (aFG for VDR and px for ESR1) and BMD, BMI, fat mass, lean mass and PFM in 400 unrelated sons using GLM-ANOVA. There was no 
significant association between the aFG haplotype and BMD, BMI, fat mass, lean mass or PFM (data no shown). There was, however, significant association between the px haplotype and BMD at the lumbar spine $(P=0.011)$ and total hip $(P=0.048)$. Subjects carrying two copies of the px haplotype had higher BMD at the lumbar spine and total hip compared with those carrying no copy of the px haplotype $(P=0.004$ and $P=0.032$, respectively) (Table 5). No relationship between such combinations of genotypes and peak BMD or obesity phenotypes in 400 unrelated sons was found using two-way analysis of variance.

\section{Discussion}

Extensive population-based association studies have been performed in different ethnic groups to test the relationships between $V D R$ and ESR1 genotypes and BMD variation ${ }^{[32,33]}$. However, the results have been inconsistent or even contradictory. Our previous study did not find any relationship between ApaI genotypes and BMD in Chinese nuclear families ${ }^{[34]}$, and this did not agree with Dundar's findings which indicated that the VDR ApaI polymorphism may be responsible for an important part of the heritable component of lumbar spine BMD in postmenopausal women ${ }^{[35]}$. Lau et al ${ }^{[36]}$ reported that the VDR FokI polymorphism may have a weak effect on the BMD of elderly Chinese women, but Remes et $a l^{[37]}$ failed to find any association between VDR FokI and ApaI polymorphisms on BMD in middle-aged men. We found that ESR1 PvuII and $X b a I$ polymorphisms may have minor effects on peak BMD in Chinese women ${ }^{[24,25]}$, and another study ${ }^{[38]}$ also found that the ESR1 PvuII and XbaI genotypes may modulate the relationship between BMD in men. However, Finnish researchers failed to support the opinion that the ESR1 XbaI and PvuII polymorphisms have a substantial impact on the development of peak bone mass in young men ${ }^{[39]}$. This may be due to the ethnic difference of the participants, to some specific effects of the gene mutation, and/or different genetic architecture and allele frequencies. In this study, we collected 400 Chinese male nuclear families, and used TDTs to simultaneously test linkage and/ or association of the VDR and ESR1 gene polymorphisms with peak BMD. We found that $V D R$ and ESR1 genotypes were not associated with lumbar spine and hip BMD in young Chinese males. Moreover, no significant within-family association was found between the VDR and ESR1 haplotypes and peak BMD. Long et al's study ${ }^{[40]}$ suggested that the ESR1 haplotypes, not single markers, may be associated with BMD variation at some skeletal sites in Chinese male samples. This result is in partial agreement with our findings. Therefore, further studies in other ethnic male populations are needed to better define the relationship between $V D R$ and ESR1 genotypes and BMD.

Although the importance of the VDR and ESR1 genes to bone biology is widely acknowledged, their importance to obesity is seldom reported. Obesity is an excess proportion of total body fat. Several studies have shown that body weight is the most common index of obesity, but it cannot be used to distinguish body fat from lean mass. More defined phenotypes have been proposed for studying obesity, such as fat
Table 8. Frequencies of VDR and ESR1 haplotypes for all parents in the study.

\begin{tabular}{cccccccc}
\hline \multicolumn{10}{l}{ VDR gene } \\
\hline \multicolumn{10}{l}{ ESR1 gene } \\
Index & Haplotype & $n$ & Frequency & Index Haplotype & $n$ & Frequency \\
1 & aFG & 325 & 0.203 & 1 & px & 966 & 0.604 \\
2 & aFA & 278 & 0.174 & 2 & pX & 77 & 0.048 \\
3 & afG & 272 & 0.170 & 3 & Px & 269 & 0.168 \\
4 & afA & 238 & 0.149 & 4 & PX & 288 & 0.180 \\
5 & AFG & 131 & 0.082 & & & & \\
6 & AFA & 121 & 0.076 & & & & \\
7 & AfG & 128 & 0.080 & & & & \\
8 & AfA & 107 & 0.067 & & & & \\
\hline
\end{tabular}

mass, lean mass, and percentage fat mass. Genetic variation in VDR is associated with muscle strength, fat mass, and body weight in Swedish women ${ }^{[3]}$. Recently, however, Moreno et $a l^{[41]}$ failed to find an association between VDR genotypes and haplotypes with fat-free mass in postmenopausal Brazilian women. Roht's research ${ }^{[42]}$ showed that VDR genotype is associated with fat-free mass in elderly Caucasian men. In the present study, we measured whole body fat mass, lean mass, and FPM as indices of the degree of obesity, using DXA. Using ANOVA and QTDT, we all found that CDX2 was significantly associated with BMI, fat mass, and PFM, and PvuII was significantly associated with fat mass and PFM. Haplotype analysis also supported the above findings. These results are inconsistent with findings in Caucasian populations; evidence of a possible link between genetic variation in ESR1 and obesity is provided by the observation that the PvuII polymorphism is associated with fat mass in women but not men ${ }^{[43]}$. However, Grundberg et al ${ }^{[44]}$ found that a TA-repeat polymorphism in the ESR1 gene did not correlate with muscle strength or body composition in young adult Swedish women. This may be due to the difference of the participants, especially sex and menopause-associated changes.

The present study differs from most other studies in the following three characteristics. First, most of the studies mentioned above were based on the traditional population association approach, which is susceptible to population structure and with which it is easy to generate spurious results. In this study, we applied a more robust method, QTDT, to estimate the relationship between polymorphisms in the $V D R$ and ESR1 genes with spine and hip BMD. Peak BMD is thought to be under strong genetic control. In our sample, the heritability estimates for peak BMD in the spine, femoral neck, and hip are $0.565,0.702$, and 0.693 , respectively. Second, we have now learned that lean mass and fat mass may be important determinants of the $\mathrm{BMD}^{[45,46]}$. Many previous studies used BMD as a surrogate marker of bone strength, which did not take into account determinants of bone strength $(e g$, fat mass, lean mass and PFM) other than bone mass. Additionally, few studies have focused on the association of genetic polymorphisms with fat mass and lean mass. To our knowledge, this is the first study to investigate the possible influence of $V D R$ and 
ESR1 genotypes and haplotypes to BMD, BMI, fat mass, lean mass, and FPM variation in Chinese males. Third, we used a relatively large sample of male offspring nuclear families.

Of course, our study has several limitations. We tested only five common loci in the two genes, so we cannot rule out the possibility that association may exist between other polymorphisms in the genes with bone and obesity phenotypes. Therefore, further studies using denser markers are needed to test the effects of the VDR and ESR1 genes (and other candidate genes) in the Chinese or other populations. In addition, because all nuclear families were represented by only two generations in this study, no sibling pairs were informative for the linkage analyses. As a result, no linkage for the $V D R$ or ESR1 genotypes and haplotypes with BMD, BMI, fat mass, lean mass, and PFM were detected.

In conclusion, our results showed that the VDR and ESR1 polymorphisms were associated with fat mass in young Chinese men, but we failed to find a significant association between these polymorphisms and peak BMD. These findings suggested that the VDR and ESR1 genes are the QTL underlying fat mass variation in young Chinese men. Confirmation of our results is needed in other populations and with more functional markers of the two genes.

\section{Acknowledgements}

The study was supported by the National Natural Science Foundation of China (NSFC) (No 30570891, 30771019, and 30800387) and Program of Shanghai Chief Scientist (Project No 08XD1403000). We wish to thank three anonymous reviewers for comments that helped to improve the manuscript and our future research.

\section{Author contribution}

Zhen-lin ZHANG designed research; Jie-mei GU, Wen-jin XIAO, Jin-wei HE, and Wen-zhen FU performed research; Hao ZHANG, Wei-wei HU, Yun-qiu HU, Miao LI, Yu-juan LIU, Jin-bo YU, Gao GAO, Hua YUE, and Yao-hua KE recruited subjects; jie-mei GU and Zhen-lin ZHANG wrote the paper.

\section{References}

1 Liu YZ, Pei YF, Liu JF, Yang F, Guo Y, Zhang L, et al. Powerful bivariate genome-wide association analyses suggest the SOX6 gene influencing both obesity and osteoporosis phenotypes in males. PLoS One 2009; 4: e6827.

2 Song MY, Ruts E, Kim J, Janumala I, Heymsfield S, Gallagher D, et al. Sarcopenia and increased adipose tissue infiltration of muscle in elderly African American women. Am J Clin Nutr 2004; 79: 874-80.

3 Grundberg E, Brandstrom H, Ribom EL, Ljunggren O, Mallmin H, Kindmark A. Genetic variation in the human vitamin $D$ receptor is associated with muscle strength, fat mass and body weight in Swedish women. Eur J Endocrinol 2004; 150: 323-8.

4 Zhang ZL, He JW, Qin YJ, Hu YQ, Li M, Zhang H, et al. Association between myostatin gene polymorphisms and peak BMD variation in Chinese nuclear families. Osteoporosis Int 2008; 19: 39-47.

5 Liu YJ, Xu FH, Shen H, Liu YZ, Deng HY, Zhao L, et al. A follow-up linkage study for quantitative trait loci contributing to obesity-related phenotypes. J Clin Endocrinol Metab 2004; 89: 875-82.
6 Rankinen T, Zuberi A, Chagnon YC, Weisnagel SJ, Argyropoulos G, Walts B, et al. The human obesity gene map: the 2005 update. Obesity 2006; 14: 529-644.

7 Tang ZH, Xiao P, Lei SF, Deng FY, Zhao $\sqcup$, et al. A bivariate wholegenome linkage scan suggests several shared genomic regions for obesity and osteoporosis. J Clin Endocrinol Metab 2007; 92: 2751-7.

8 Uitterlinden AG, Fang Y, Bergink AP, van Meurs JB, van Leeuwen HP, Pols HA. The role of vitamin $D$ receptor gene polymorphisms in bone biology. Mol Cell Endocrinol 2002;197: 15-21.

9 Dace A, Martin-el Yazidi C, Bonne J, Planells R , Torresani J. Calcitriol is a positive effector of adipose differentiation in the OB 17 cell line: relationship with the adipogenic action of triiodothyronine. Biochem Biophys Res Commun 1997; 232: 771-6.

10 Giuffrida D, Lupo L, La Porta GA, La Rosa GL, Padova G, Foti E, et al. Relation between steroid receptor status and body weight in breast cancer patients. Eur J Cancer 1992; 28: 112-5.

11 Joyner JM, Hutley LJ, Cameron DP. Estrogen receptors in human preadipocytes. Endocrine 2001; 15: 225-30.

12 Okura T, Koda M, Ando F, Niino N, Ohta S, Shimokata H. Association of polymorphisms in the estrogen receptor alpha gene with body fat distribution. Int J Obes Relat Metab Disord 2003; 27: 1020-7.

13 Deng HW, Li J, Li JL, Dowd R, Davies KM, Johnson M, et al. Association of estrogen receptor alpha genotypes with body mass index in normal healthy postmenopausal Caucasian women. J Clin Endocrinol Metab 2000; 85: 2748-51.

14 Mazess RB, Barden HS, Bisek JP, Hanson J. Dual-energy x-ray absorptiometry for total-body and regional bone-mineral and softtissue composition. Am J Clin Nutr 1990; 51: 1106-12.

15 Svendsen OL, Haarbo J, Hassager C, Christiansen C. Accuracy of measurements of body composition by dual-energy X-ray absorptiometry in vivo. Am J Clin Nutr 1993; 57: 605-8.

16 Deng HW, Deng HY, Liu YJ, Liu YZ, Xu FH, Shen H, et al. A genomewide linkage scan for quantitative-trait loci for obesity phenotypes. Am J Hum Genet 2002; 70: 1138-51.

17 Jiang $\mathrm{H}$, Xiong DH, Guo YF, Shen $\mathrm{H}$, Xiao P, Yang F, et al Association analysis of vitamin D-binding protein gene polymorphisms with variations of obesity-related traits in Caucasian nuclear families. Int J Obes 2007: 31: 1319-24.

18 Gao G, Zhang ZL, Zhang H, Hu WW, Huang QR, Lu JH, et al. Hip axis length changes in 10554 males and females and the association with femoral neck fracture. J Clin Densitiom 2008; 11: 360-6.

19 Harris SS, Eccleshall TR, Gross C, Dawson-Hughes B, Feldman D. The vitamin $\mathrm{D}$ receptor start codon polymorphism (Fok I) and bone mineral density in premenopausal American Black and White women. J Bone Miner Res 1997; 12: 1043-8.

20 Zmuda JM, Cauley JA, Danielson ME, Wolf RL, Ferrell RE. Vitamin $\mathrm{D}$ receptor gene polymorphisms, bone turnover, and rates of bone loss in older African-American women. J Bone Miner Res 1997; 12: 1446-52.

21 Fang $\mathrm{Y}$, van Meurs JB, Bergink AP, Hofman A, van Duijn CM, van Leeuwen JP, et al. Cdx-2 polymorphism in the promoter region of the human vitamin $D$ receptor gene determiners susceptibility to fracture in the elderly. J Bone Mineral Res 2003; 18: 1632-41.

22 Zhang ZL, He JW, Huang QR, Qin YJ, Hu YQ, Li M, et al. Relationship between the polymorphism of start codon and CDX2 site in vitamin $D$ receptor gene and the effect of calcium supplementation on bone mineral density of postmenopausal women. Zhonghua Yi Xue Yi Chuan Xue Za Zhi 2006; 23: 397-401.

23 Kobayashi S, Inoue S, Hosoi T, Ouchi Y, Shiraki M, Orimo H. Association of bone mineral density with polymorphism of the estrogen receptor gene. J Bone Miner Res 1996; 11: 306-11. 
24 Qin YJ, Zhang ZL, Huang QR, He JM, Hu YQ, Zhao Q, et al. Association of vitamin $\mathrm{D}$ receptor and estrogen receptor-alpha gene polymorphism with peak bone mass and bone size in Chinese women. Acta Pharmacol Sin 2004; 25: 462-8.

25 Qin YJ, Shen H, Huang QR, Zhao L, Zhou Q, Li MX, et al. Estrogen receptor $\alpha$ gene polymorphisms and peak bone density in Chinese nuclear families. J Bone Miner Res 2003; 18: 1028-35.

26 Abecasis GR, Cardon LR, Cookson WO. A general test of association for quantitative traits in nuclear families. Am J Hum Genet 2000; 66: 279-92.

27 Koller DL, Ichikawa S, Johnson ML, Lai D, Xuei X, Edenberg HJ, et al. Contribution of the LRP5 gene to normal variation in peak BMD in women. J Bone Mineral Res 2005; 20: 75-80.

28 Zhang ZL, He JW, Qin YJ, Hu YQ, Li M, Liu YJ, et al. Association between the SNPs and haplotypes in the PPARGC1 and adiponectin genes and bone mineral density in Chinese women and men. Acta Pharmocal Sin 2007; 28: 287-95.

29 Deng FY, Liu MY, Li MX, Lei SF, Qin YJ, Zhou Q, et al. Test of linkage and association of the COL1A2 gene with bone phenotypes' variation in Chinese nuclear families. Bone 2003; 33: 614-9.

30 Lau HH, Ng MY, Cheung WM, Paterson AD, Sham PC, Luk KD, et al. Assessment of linkage and association of 13 genetic loci with bone mineral density. J Bone Miner Metab 2006; 24: 226-34.

31 McIntyre LM, Martin ER, Simonsen KL, Kaplan NL. Circumventing multiple testing: a multilocus Monte Carlo approach to testing for association. Genet Epidemiol 2000; 19: 18-29.

32 Zhang ZL, Zhao JX, Meng XW, Zhou XY, Xing XP, Xia WB. Association of polymorphisms of vitamin $D$ receptor gene start codon and $3^{\prime}$ end region with bone mineral density in postmenopausal women. Zhonghua Yi Xue Yi Chuan Xue Za Zhi, 2003; 20: 5-8.

33 Choi YM, Jun JK, Choe J, Hwang D, Park SH, Ku SY, et al. Association of the vitamin $\mathrm{D}$ receptor start codon polymorphism (Fok I) with bone mineral density in postmenopausal Korean women. J Hum Genet 2000; 45: 280-3.

34 Qin YJ, Zhang ZL, Huang QR, He JW, Hu YQ, Zhou Q, et al. Association of vitamin $\mathrm{D}$ receptor gene Apa I polymorphism with peak bone density in Chinese nuclear families. Chin J Osteoporosis 2006; 12: 4-7. Chinese.

35 Dundar U, Solak M, Kavuncu V, Ozdemir M, Cakir T, Yildiz H. Evidence of association of Vitamin D receptor Apa I gene polymorphism with bone mineral density in postmenopausal women with osteoporosis. Clin Rheumatol. 2009; 28: 1187-91.

36 Lau EM, Lam V, Li M, Ho K, Woo J. Vitamin D receptor start codon polymorphism (Fok I) and bone mineral density in Chinese men and women. Osteoporos Int 2002; 13: 218-21.

37 Remes T, Väisänen SB, Mahonen A, Huuskonen J, Kröger H, Jurvelin $\mathrm{JS}$, et al. Bone mineral density, body height, and vitamin $\mathrm{D}$ receptor gene polymorphism in middle-aged men. Ann Med 2005; 37: 38392.

38 Khosla S, Riggs BL, Atkinson EJ, Oberg AL, Mavilia C, Del Monte F, et al. Relationship of estrogen receptor genotypes to bone mineral density and to rates of bone loss in men. J Clin Endocrinol Metab 2004; 89: 1808-16.

39 Välimäki VV, Piippo K, Välimäki S, Löyttyniemi E, Kontula K, Välimäki MJ. The relation of the Xba I and Pvu II polymorphisms of the estrogen receptor gene and the CAG repeat polymorphism of the androgen receptor gene to peak bone mass and bone turnover rate among young healthy men. Osteoporos Int 2005; 16: 1633-40.

40 Long JR, Zhang YY, Liu PY, Liu YJ, Shen H, Dvornyk V, et al. Association of estrogen receptor alpha and vitamin $D$ receptor gene polymorphisms with bone mineral density in Chinese males. Calcif Tissue Int 2004; 74: 270-6.

41 Moreno Lima R, Silva de Abreu B, Gentil P, Cesar de Lima Lins T, Grattapaglia D, Pereira RW. Lack of association between vitamin D receptor genotypes and haplotypes with fat-free mass in postmenopausal Brazilian women. J Gerontol A Biol Sci Med Sci 2007; 62: 966-72.

42 Roth SM, Zmuda JM, Cauley JA, Shea PR, Ferrell RE. Vitamin D receptor genotype is associated with fat-free mass and sarcopenia in elderly men. J Gerontol A Biol Sci Med Sci 2004; 59: 10-5.

43 Okura T, Koda M, Ando F, Niino N, Ohta S, Shimokata H. Association of polymorphisms in the estrogen receptor gene with body fat distribution. Int J Obes Relat Metab Disord 2003; 27: 1020-7.

44 Grundberg E, Ribom EL, Brändström H, Ljunggren O, Mallmin H, Kindmark A. A TA-repeat polymorphism in the gene for the estrogen receptor alpha does not correlate with muscle strength or body composition in young adult Swedish women. Maturitas 2005; 50: 153-60.

45 Cui LH, Shin MH, Kweon SS, Park KS, Lee YH, Chung EK, et al. Relative contribution of body composition to bone mineral density at different sites in men and women of South Korea. J Bone Miner Metab 2007; 25: 165-71.

46 Gillette-Guyonnet S, Nourhashemi F, Lauque S, Grandjean H, Vellas B. Body composition and osteoporosis in elderly women. Gerontology 2000; 46: 189-93. 